\title{
Rehabilitation After Anterior Cruciate Ligament Reconstruction
}

\author{
A Systematic Review \\ L.M. Kruse, MD, B. Gray, MD, and R.W. Wright, MD \\ Investigation performed at the Department of Orthopedic Surgery, Washington University School of Medicine, St. Louis, Missouri
}

\begin{abstract}
Background: Rigorous rehabilitation after anterior cruciate ligament (ACL) reconstruction is necessary for a successful surgical outcome. A large number of clinical trials continue to assess aspects of this rehabilitation process. Prior systematic reviews evaluated fifty-four Level-I and II clinical trials published through 2005.
\end{abstract}

Methods: Eighty-five articles from 2006 to 2010 were identified utilizing multiple search engines. Twenty-nine LevelI or II studies met inclusion criteria and were evaluated with use of the CONSORT (Consolidated Standards of Reporting Trials) criteria. Topics included in this review are postoperative bracing, accelerated strengthening, homebased rehabilitation, proprioception and neuromuscular training, and six miscellaneous topics investigated in single trials.

Results: Bracing following ACL reconstruction remains neither necessary nor beneficial and adds to the cost of the procedure. Early return to sports needs further research. Home-based rehabilitation can be successful. Although neuromuscular interventions are not likely to be harmful to patients, they are also not likely to yield large improvements in outcomes or help patients return to sports faster. Thus, they should not be performed to the exclusion of strengthening and range-of-motion exercises. Vibration training may lead to faster and more complete proprioceptive recovery but further evidence is needed.

Conclusions: Several new modalities for rehabilitation after ACL reconstruction may be helpful but should not be performed to the exclusion of range-of-motion, strengthening, and functional exercises. Accelerated rehabilitation does not appear to be harmful but further investigation of rehabilitation timing is warranted.

Level of Evidence: Therapeutic Level II. See Instructions for Authors for a complete description of levels of evidence.

$\mathrm{S}$ uccessful anterior cruciate ligament (ACL) reconstruction requires physical rehabilitation to help patients return to an active lifestyle. Prior systematic reviews by Wright et al. in 2008 included fifty-four studies with Level-I or II evidence published through 2005 (Table I) ${ }^{1,2}$. Since 2005, numerous studies have evaluated the safety of accelerated and brace-free rehabilitation protocols that

Disclosure: None of the authors received payments or services, either directly or indirectly (i.e., via his or her institution), from a third party in support of any aspect of this work. One or more of the authors, or his or her institution, has had a financial relationship, in the thirty-six months prior to submission of this work, with an entity in the biomedical arena that could be perceived to influence or have the potential to influence what is written in this work. No author has had any other relationships, or has engaged in any other activities, that could be perceived to influence or have the potential to influence what is written in this work. The complete Disclosures of Potential Conflicts of Interest submitted by authors are always provided with the online version of the article. attempt to return athletes to sports more quickly ${ }^{3-11}$. Several studies investigated the use of bracing for additional benefits such as pain control ${ }^{12-14}$. Additionally, longer-term data from previously published trials are becoming available $e^{15-17}$. The present systematic review methodically evaluates studies on rehabilitation following ACL reconstruction that have LevelI or II evidence and have been published since the previous

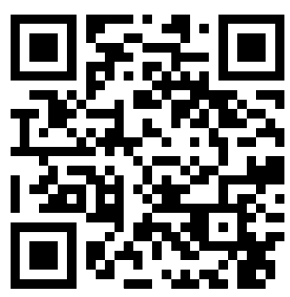

A commentary by Robert J. Johnson, MD, and Bruce D. Beynnon, PhD, is linked to the online version of this article at jbjs.org. 
The Journal of Bone \& Joint Surgery - Jbjs.org Volume 94-A • Number $19 \cdot$ OCtober 3, 2012

Rehabilitation After Anterior Cruciate

LigAMENT RECONSTRUCTION

TABLE I Summary of the Prior Systematic Reviews on Rehabilitation Following ACL Reconstruction

\begin{tabular}{|lrl|l|}
\hline \multicolumn{1}{|c|}{ Rehabilitation Investigated } & No. of Studies & Results \\
\hline CPM* & 6 & No advantage to CPM use \\
Early weight-bearing and motion & 2 & No adverse effects of early weight-bearing and motion \\
Postoperative bracing & 11 & No advantage to postoperative bracing \\
Home-based physical therapy & 4 & Can be successful in motivated patients \\
Open vs. closed-kinetic-chain exercises & 5 & Open-chain exercises may be safely started at 6 weeks \\
Electrical stimulation & 14 & postoperatively although further evidence is needed \\
Accelerated vs. 5 to 6-month rehab. & 2 & May be safe but additional data are needed to strengthen conclusions \\
Miscellaneous topics & 10 & Water therapy and stair climber and slide board exercises are safe; \\
& & psychological and proprioceptive training may be beneficial; creatine \\
*CPM $=$ continuous passive motion. & & \\
\hline
\end{tabular}

systematic reviews. It provides recommendations on the inclusion of these new protocols into an ACL rehabilitation program.

\section{Materials and Methods}

DubMed, Embase, and the Cochrane Controlled Trials Register were searched P using the terms "anterior cruciate ligament reconstruction," "ACL," "rehabilitation," "randomized trial," and "clinical trial" to identify studies published from January 2006 to December 2010. The search was performed in triplicate by the three authors and the results were reconciled (Fig. 1), resulting in identification of eighty-five articles. Determination of study evidence level was based on recommendations by the Centre for Evidence-based Medicine ${ }^{18}$ and included high-quality randomized controlled trials as Level-I studies and lesser-quality randomized controlled trials and prospective comparative studies as Level-II studies. This review excluded case-control studies, retrospective comparative studies, and case series. The eighty-five identified articles were reviewed, and thirty-four potentially met the inclusion criteria of peer-reviewed Englishlanguage articles published from January 2006 to December 2010 and describing Level-I and II clinical trials evaluating ACL rehabilitation. Exclusion criteria included non-English language, non-Level-I or II studies, irrelevant subject matter, systematic reviews, and conference and meeting abstracts. This resulted in the inclusion of twenty-nine studies. Two of these studies presented long-term results of studies included in the previously systematic reviews.

Data extracted from the analyzed articles included the level of evidence, number of patients, ACL reconstruction method, randomization procedure, differences between groups, intervention, loss to follow-up, parameters assessed, significant findings, bias, and conclusions. Quality appraisal was performed by all three authors with use of the CONSORT (Consolidated Standards of Reporting Trials) 2010 checklist of information to include when

\section{TABLE II Summary of Studies on Postoperative Bracing*}

Study (Level of Evidence)

No. of Patients/Groups

Hiemstra et al. ${ }^{12}$ (I)

$88 / 2$

$73 / 2$

Mayr et al. ${ }^{14}$ (I)

Birmingham et al. ${ }^{13}$ (I)

$150 / 2$

Ito et al. ${ }^{4}$ (II)

Harilainen and Sandelin ${ }^{15}(\mathrm{II}) \dagger$

Isberg et al. ${ }^{3}$ (II)
$30 / 2$

$60 / 2$
Group Differences

Knee immobilization for 14 days vs. no immobilization

Hard brace vs. water-filled soft brace

Functional brace vs. neoprene sleeve during activity

Immobilization for 3 days vs. 2 weeks

Brace for 2 weeks vs. no brace

Restricted motion vs. no range of motion restriction for 1 month
Day of surgery

Birth year

Computer-generated, variable block size

Opaque envelope

Computer-generated random list

Opaque envelope

*VAS = visual analog scale, IKDC = International Knee Documentation Committee, $\mathrm{QOL}=$ quality of life, and BTB = bone-patellar tendon-bone. †Long-term follow-up of a study included in the previous systematic reviews. 
The Journal of Bone \& Joint Surgery $\cdot$ JBjS. Org Volume 94-A • Number $19 \cdot$ OCtober 3, 2012
Rehabilitation After Anterior Cruciate

LigAMENT RECONSTRUCTION

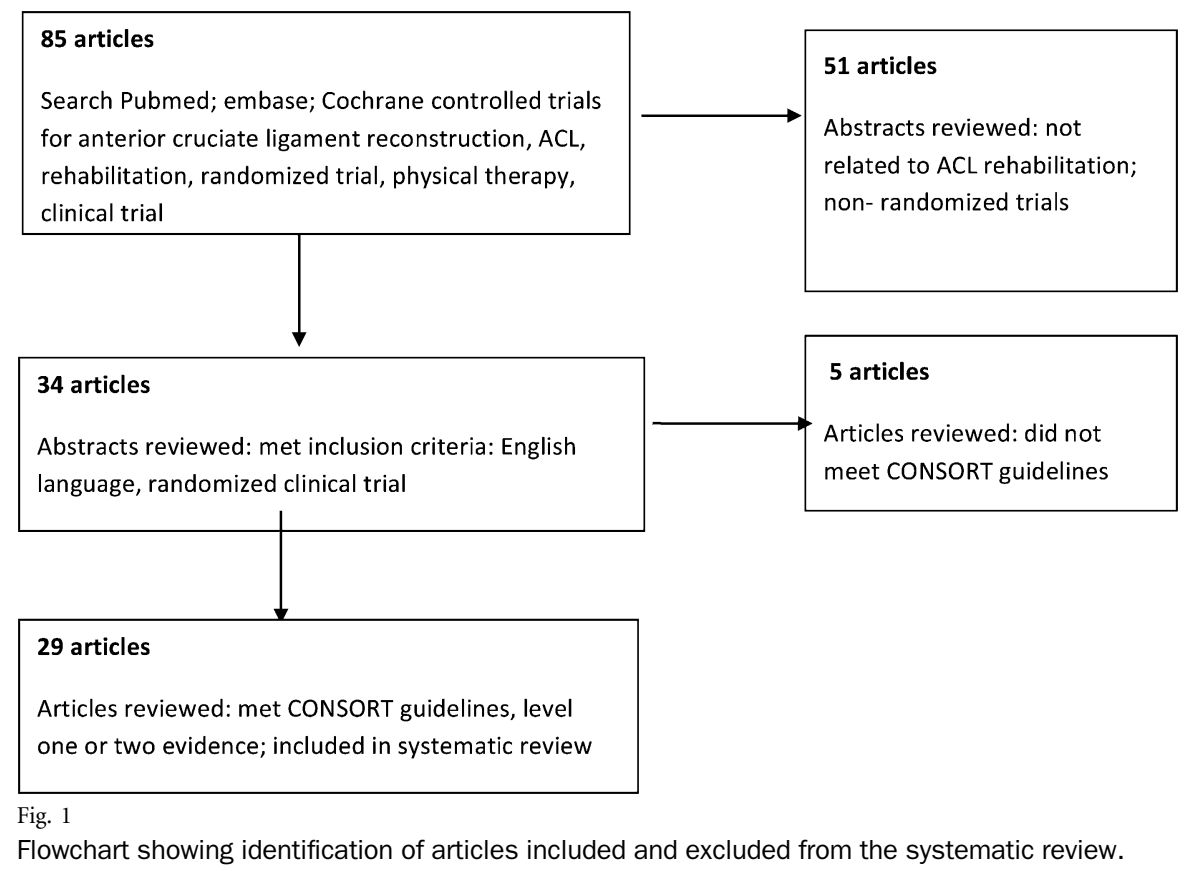

reporting a randomized trial ${ }^{19}$. Results and conclusions from these studies were summarized and recommendations were made. This review includes postoperative bracing, accelerated rehabilitation, home-based rehabilitation, proprioception and neuromuscular training, and miscellaneous topics investigated by single trials.

\section{Results}

\section{Postoperative Bracing}

Dostoperative bracing, designed to limit or improve range of motion and to protect against varus and valgus stress, has not been found to improve ACL recovery and rehabilitation in the studies included in the previous systematic reviews ${ }^{2}$. Bracing did not protect against postoperative injury, decrease pain, alter range of knee motion, or improve knee stability. Six additional randomized controlled trials have since been published (Table II) (3,4,12-15. $^{\text {. }}$

Hiemstra et al. ${ }^{12}$ performed a randomized controlled trial comparing knee immobilization with no bracing following ACL reconstruction with hamstring tendon; early pain was assessed in eighty-eight patients randomized by computer into two groups. The primary outcome was patient pain self-assessed

\section{TABLE II (continued)}

\begin{tabular}{|c|c|c|c|}
\hline Parameters Assessed & Significant Findings & ACL Method & Bias \\
\hline $\begin{array}{l}\text { ACL-QOL, laxity with KT1000, } \\
\text { single-limb hop, Tegner }\end{array}$ & $\begin{array}{l}\text { No difference at } 12 \text { or } 24 \text { months, } \\
\text { braced patients had higher } \\
\text { subjective confidence }\end{array}$ & Hamstring autograft & Selection \\
\hline $\begin{array}{l}\text { Laxity with KT2000, stability with } \\
\text { Biodex system, strength }\end{array}$ & $\begin{array}{l}\text { No significant differences } \\
\text { at } 3,6 \text {, or } 12 \text { months }\end{array}$ & Hamstring autograft & Selection \\
\hline $\begin{array}{l}\text { Lysholm, Tegner, laxity, } \\
\text { isokinetic strength }\end{array}$ & $\begin{array}{l}\text { 5-year follow-up continued } \\
\text { to show no difference }\end{array}$ & BTB & Selection \\
\hline $\begin{array}{l}\text { Radiostereometric analysis, laxity } \\
\text { with KT1000, range of motion, } \\
\text { Tegner, Lysholm, single-leg hop }\end{array}$ & $\begin{array}{l}\text { No differences at } 6 \\
\text { months or } 2 \text { years }\end{array}$ & BTB & Possibly underpowered \\
\hline
\end{tabular}




\begin{tabular}{|c|c|c|c|}
\hline Study (Level of Evidence) & No. of Patients/Groups & Group Differences & Randomization \\
\hline Gerber et al. ${ }^{10}(\mathrm{I})$ & $32 / 2$ & $\begin{array}{l}\text { Eccentric strengthening vs. } \\
\text { traditional strengthening }\end{array}$ & Coin flip, matched \\
\hline Gerber et al..$^{8,9}(\mathrm{I})$ & $40 / 2$ & $\begin{array}{l}\text { Eccentric strengthening vs. } \\
\text { traditional strengthening }\end{array}$ & Coin flip, matched \\
\hline Shaw et al. ${ }^{6}(\mathrm{I})$ & $103 / 2$ & $\begin{array}{l}\text { Strengthening immediately vs. } \\
\text { at } 2 \text { weeks }\end{array}$ & Concealed method \\
\hline Sekir et al. ${ }^{7}$ (II) & $48 / 2$ & $\begin{array}{l}\text { Isokinetic hamstring } \\
\text { strengthening at } 3 \text { weeks vs. } \\
9 \text { weeks }\end{array}$ & $\begin{array}{l}\text { Sealed opaque } \\
\text { envelopes }\end{array}$ \\
\hline Vadalà et al. ${ }^{11}$ (II) & $45 / 2$ & $\begin{array}{l}\text { Accelerated vs. } \\
\text { standard rehab. }\end{array}$ & Draw \\
\hline
\end{tabular}

*VAS = visual analog scale, KOS-ADLS = Activities of Daily Living Scale of the Knee Outcome Survey, BTB = bone-patellar tendon-bone, MRI = magnetic resonance imaging, IKDC = International Knee Documentation Committee, and CT = computed tomography.

with use of a visual analog scale (VAS) at two days after surgery, with secondary outcomes including analgesic use, VAS pain, knee motion, knee effusion, and wound-healing throughout the first fourteen days after surgery. Patients were permitted full weight-bearing and wore a knee immobilizer at all times except during strengthening and range-ofmotion exercises. There was no difference in pain, analgesic use, range of motion, or effusion at two or fourteen days. One patient in the immobilization group and five patients in the non-immobilization group had wound scabbing; these were the only wound complications noted. This study had a treatment bias because of low compliance with use of the knee immobilizer.

Mayr et al. ${ }^{14}$ randomized seventy-three patients to all-day wear of either a hard rehabilitation brace or a soft, compressible, fluid-filled rehabilitation brace for six weeks. Maximum flexion was limited to $90^{\circ}$ until twelve days after surgery and not limited thereafter. The authors found decreased early effusion with the soft brace $(\mathrm{p}<0.05)$ and no difference in thigh atrophy, knee motion, or knee laxity. Statistically greater International Knee Documentation Committee (IKDC) scores were noted with the soft brace from six weeks to twelve months postoperatively ( $p<0.05$ ), but this difference was less than the minimal clinically important difference ${ }^{20}$. The improvements in the Tegner and Lysholm scores between the six and twelvemonth time points were significant $(\mathrm{p}<0.05)$ but equaled $<1$ and 8.9 points, respectively; these values were less than the minimum detectable change ${ }^{21}$.

Birmingham et al. ${ }^{13}$ randomized 150 patients at six weeks after surgery to use of either a functional brace or a neoprene sleeve during rehabilitation exercises and all physical activities. Compliance with brace wear was measured at six and twelve months. Patients were assessed with use of the ACL Quality of Life (ACL-QOL) questionnaire, KT1000 arthrometer, singlelimb hop test, and Tegner activity scale at twelve and twenty-four months. No significant differences in compliance or outcome measures were noted, but patients treated with bracing had a higher subjective confidence rating.

Ito et al. ${ }^{4}$ randomized thirty patients immediately following ACL reconstruction with hamstring autograft to either three days or two weeks of full-time bracing that allowed knee motion from $0^{\circ}$ to $20^{\circ}$ of flexion. Range-of-motion exercises began after the completion of bracing. The specifics of the rehabilitation protocol were not stated in the study. Patients were permitted partial weight-bearing for two weeks and then weight-bearing as tolerated. Laxity, thigh muscle strength, and joint position sense were evaluated at three, six, and twelve months postoperatively with use of the KT2000 and Biodex systems. No significant differences were found between the groups, and early range of motion did not increase subsequent laxity.

Harilainen and Sandelin ${ }^{15}$ published a five-year followup of their previous report comparing an ankle-to-thigh rehabilitation knee brace with no brace in knees reconstructed with bone-patellar tendon-bone graft. Knee motion in the brace group was restricted to $0^{\circ}$ to $90^{\circ}$ for the first three weeks, $0^{\circ}$ to $120^{\circ}$ from four to six weeks, and unrestricted for the remaining six weeks. Knee motion in the no-brace group was restricted to $0^{\circ}$ to $90^{\circ}$ for three weeks and unrestricted thereafter. Both groups had limited weight-bearing for three weeks and were then allowed weight-bearing as tolerated. Sixty patients had initially been divided into two groups by birth year, and the follow-up rate at five years was $80 \%$. The Lysholm scores, Tegner activity scores, laxity, and isokinetic strength continued to show no differences between the groups at that time. Substantial attrition and potential selection bias resulting from the randomization limit the results of this study.

Isberg et al. ${ }^{3}$ assessed the effects of full active and passive extension immediately following ACL reconstruction. Twentytwo patients were randomized to either restricted motion (a brace allowing knee motion from $10^{\circ}$ of hyperextension to 


\begin{tabular}{|c|c|c|c|}
\hline Parameters Assessed & Significant Findings & ACL Method & Bias \\
\hline $\begin{array}{l}\text { VAS pain, knee effusion, laxity with KT1000, } \\
\text { strength, single-leg hop, KOS-ADLS }\end{array}$ & $\begin{array}{l}\text { No difference in pain, effusion, } \\
\text { or stability at } 14 \text { weeks }\end{array}$ & Hamstring, BTB & Selection \\
\hline $\begin{array}{l}\text { Isokinetic strength, quadriceps lag, laxity, } \\
\text { functional hop, Cincinnati knee score }\end{array}$ & $\begin{array}{l}\text { No significant differences } \\
\text { during } 6 \text { months }\end{array}$ & BTB in 63 , hamstring in 40 & Treatment \\
\hline $\begin{array}{l}\text { IKDC, Cincinnati knee score, hamstring } \\
\text { strength with Cybex } 6000\end{array}$ & $\begin{array}{l}\text { Early strengthening increased } \\
\text { strength at one month with no } \\
\text { harmful effects for } 1 \text { year }\end{array}$ & BTB & Attrition, selection \\
\hline $\begin{array}{l}\text { CT scan calculated tibial } \\
\text { and femoral tunnel diameters }\end{array}$ & $\begin{array}{l}\text { Statistically significant femoral } \\
\text { and tibial tunnel enlargement in } \\
\text { the accelerated group }\end{array}$ & Hamstring & Selection \\
\hline
\end{tabular}

$30^{\circ}$ of flexion) or bracing with no restriction on knee motion during the first month. Both groups were permitted weightbearing as tolerated. Patients were assessed for anterior-posterior laxity, knee motion, and ability to perform a one-leg hop test. Tegner and Lysholm scores were also evaluated. There was no difference between the groups at six months or two years in any of the measured outcomes. A power analysis was not presented, and thus it is possible that their sample size limited their ability to detect a difference between their groups.

As in the previous systematic reviews, no study demonstrated a clinically significant benefit to bracing or restricted range of knee motion with regard to pain control, knee laxity, or rehabilitation. Additionally, no study had worse outcomes associated with no bracing. Bracing following ACL reconstruction is still deemed neither necessary nor beneficial, and immediate postoperative range of knee motion is safe.

\section{Accelerated Strengthening}

ACL rehabilitation during the last fifteen to twenty years has been based largely on a six-month time frame for return to sports. Although the prior systematic reviews identified a paucity of studies on accelerated rehabilitation ${ }^{1}$, Beynnon et al. demonstrated that it is unlikely to be harmful ${ }^{5}$. Recently, numerous additional randomized clinical trials have evaluated the timing and safety of strengthening in accelerated compared with standard rehabilitation (Table III $)^{6-11}$.

Gerber et al. published three articles evaluating progressive eccentric exercise starting at three weeks postoperatively compared with twelve weeks $s^{8-10}$. Both groups were allowed full knee motion and performed eccentric exercises using ergometers between $20^{\circ}$ and $60^{\circ}$ of knee flexion. The initial study ${ }^{10}$ included thirty-two patients randomized to early eccentric exercise beginning at either three or twelve weeks. At fourteen weeks the authors assessed VAS pain, knee effusion, knee laxity measured with the KT1000, quadriceps strength, single-leg hopping, and the Activities of Daily Living scale of the Knee Outcome Survey (KOS-ADLS), and they found no difference in pain, effusion, or anterior laxity. A second article involving the same intervention included eight additional patients (forty total) ${ }^{8}$, and a third article presented follow-up data

\section{TABLE IV Summary of Studies on Home-Based Rehabilitation*}

\begin{tabular}{|c|c|c|c|c|c|c|c|}
\hline $\begin{array}{l}\text { Study (Level } \\
\text { of Evidence) }\end{array}$ & $\begin{array}{c}\text { No. of } \\
\text { Patients/Groups }\end{array}$ & $\begin{array}{c}\text { Group } \\
\text { Differences }\end{array}$ & Randomization & $\begin{array}{c}\text { Parameters } \\
\text { Assessed }\end{array}$ & $\begin{array}{l}\text { Significant } \\
\text { Findings }\end{array}$ & $\begin{array}{c}\text { ACL } \\
\text { Method }\end{array}$ & Bias \\
\hline $\begin{array}{l}\text { Grant and } \\
\text { Mohtadi }^{16}(\mathrm{I}) \dagger\end{array}$ & $129 / 2$ (88 returned) & $\begin{array}{l}\text { Home } \\
\text { therapy vs. } \\
\text { PT visits }\end{array}$ & $\begin{array}{l}\text { Opaque } \\
\text { envelope }\end{array}$ & $\begin{array}{l}\text { ROM, laxity, } \\
\text { strength, } \\
\text { ACL-QOL }\end{array}$ & $\begin{array}{l}\text { Greater ACL-QOL } \\
\text { in home therapy } \\
\text { group }\end{array}$ & & $\begin{array}{l}\text { Attrition, } \\
\text { performance, } \\
\text { selection }\end{array}$ \\
\hline $\begin{array}{l}\text { Revenas } \\
\text { et al. }^{24} \text { (II) }\end{array}$ & $51 / 2$ & $\begin{array}{l}\text { Knee class } \\
\text { therapy vs. } \\
\text { PT visits }\end{array}$ & Not revealed & $\begin{array}{l}\text { IKDC, } \\
\text { Lysholm, } \\
\text { Tegner, } \\
\text { strength, } \\
\text { hop test }\end{array}$ & $\begin{array}{l}\text { No differences } \\
\text { at } 6 \text { and } 12 \\
\text { months }\end{array}$ & BTB & $\begin{array}{l}\text { Selection, } \\
\text { attrition, } \\
\text { performance }\end{array}$ \\
\hline
\end{tabular}


1742

The Journal of Bone \& Joint SURgery $\cdot$ JBJS.org Volume 94-A • NUMBer $19 \cdot$ OCtOBER 3, 2012

Rehabilitation After Anterior Cruciate

LigAMENT RECONSTRUCTION

TABLE V Summary of Studies on Neuromuscular Training*

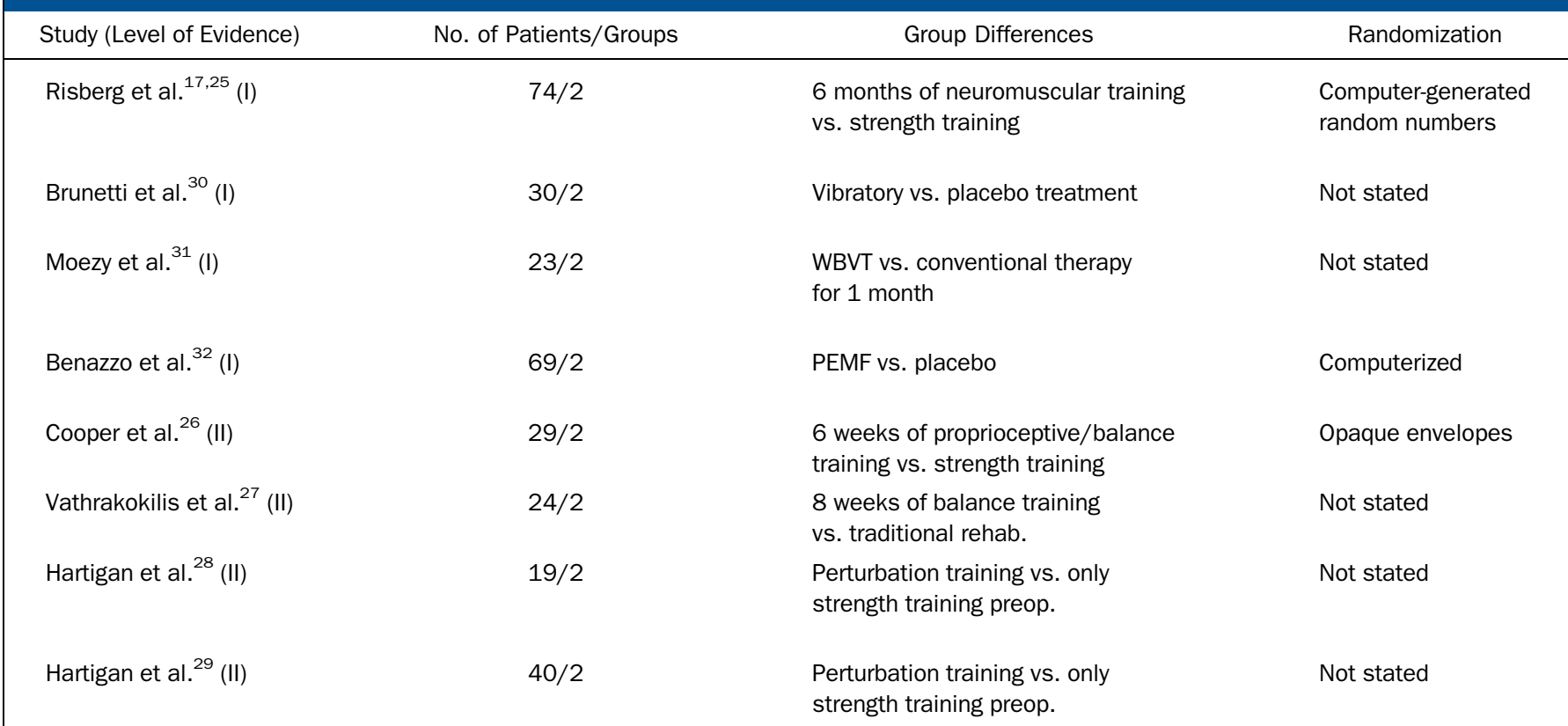

*VAS = visual analog scale, SF-36 = Short Form-36, BTB = bone-patellar tendon-bone, IKDC = International Knee Documentation Committee, WBVT $=$ whole-body vibration training, PEMF $=$ pulsed electromagnetic field, NSAID = nonsteroidal anti-inflammatory drug, and KOS-ADLS = Activities of Daily Living Scale of the Knee Outcome Survey.

for that cohort at one year ${ }^{9}$. A blinded, independent examiner evaluated quadriceps, gluteus maximus, and hamstring muscle cross-sectional area and volume preoperatively and postoperatively with use of magnetic resonance imaging (MRI). The authors measured knee laxity with the KT1000, isokinetic strength of the quadriceps and hamstrings, single-leg hopping, the Knee Outcome Survey score, and the Lysholm score. At fifteen weeks and at one year, the quadriceps and gluteus maximus muscle cross-sectional areas and volumes in the early eccentric exercise cohort were more than twice those in the later eccentric exercise group $(\mathrm{p}<0.01)$. The early eccentric group also had an increased quadriceps muscle strength index $(\mathrm{p}<0.001)$. All other factors were unaffected.

Shaw et al. ${ }^{6}$ studied early quadriceps muscle strengthening in 103 patients. One group performed straight-leg raises and isometric quadriceps contractions beginning immediately after surgery, and the other group did not. After two weeks, all patients underwent the same therapy regimen. The authors found no significant difference in isokinetic quadriceps strength, quadriceps lag, knee laxity, functional hop testing, or the Cincinnati knee score during six months of follow-up.

Sekir et al. ${ }^{7}$ studied early isokinetic hamstring strengthening after ACL reconstruction with patellar tendon autograft. Forty-eight patients were randomly assigned to start hamstring strengthening at either three or nine weeks postoperatively. They were evaluated monthly for four months and at one year postoperatively with use of the IKDC score, Cincinnati knee score, and hamstring isometric and isokinetic strength. Early strength- ening was associated with increased early isometric hamstring strength $(\mathrm{p}<0.01)$ and increased isokinetic hamstring strength at $60^{\circ}$ second (a difference of approximately $20 \mathrm{Nm}, \mathrm{p}<0.05$ ). The early strengthening group also had improved Cincinnati knee subscores for the swelling and giving-way domains but not for the pain domain. The early strengthening group had clinically significant improvements in activities of daily living at one month, but they had no difference in IKDC scores. Early hamstring strengthening had no harmful effects. This study was limited by attrition bias since $<50 \%$ of patients completed the one-year follow-up.

Vadalà et al. ${ }^{11}$ randomized forty-five patients after ACL reconstruction with hamstring autograft to either accelerated brace-free rehabilitation (immediate knee motion, weightbearing as tolerated on postoperative day two, immediate isometric and isotonic exercises), or standard rehabilitation (two weeks of bracing and isometric exercises, then active knee motion until six weeks, when isotonic and isokinetic exercises were initiated). The authors used computed tomography to calculate tibial and femoral tunnel diameters immediately postoperatively and at ten months of follow-up. The mean femoral tunnel diameter increased significantly from $9.04 \pm$ $0.05 \mathrm{~mm}$ postoperatively to $9.30 \pm 0.8 \mathrm{~mm}$ at follow-up in the standard rehabilitation group and from $9.04 \pm 0.03$ to $9.94 \pm$ $1.12 \mathrm{~mm}$ in the accelerated rehabilitation group $(\mathrm{p}<0.002)$. The mean tibial tunnel diameter increased significantly from $9.03 \pm 0.04$ to $10.01 \pm 0.80 \mathrm{~mm}$ in the standard rehabilitation group and from $9.04 \pm 0.03$ to $10.60 \pm 0.78 \mathrm{~mm}$ in the accelerated rehabilitation group $(\mathrm{p}<0.001)$. Although these 
TABLE V (continued)

\begin{tabular}{|c|c|c|c|}
\hline Parameters Assessed & Significant Findings & ACL Method & Bias \\
\hline $\begin{array}{l}\text { Single-leg balance, quadriceps torque, } \\
\text { IKDC, SF-36 }\end{array}$ & $\begin{array}{l}\text { Improved single-limb balance, improved } \\
\text { torque at } 90 \text { and } 270 \text { days }\end{array}$ & Hamstring & Selection \\
\hline Postural stability, proprioception & $\begin{array}{l}\text { WBVT group had greater improvements } \\
\text { in stability and proprioception } \\
\text { following treatment }\end{array}$ & BTB & $\begin{array}{l}\text { No long-term } \\
\text { follow-up }\end{array}$ \\
\hline IKDC, SF-36, VAS, NSAID use & $\begin{array}{l}\text { Faster recovery and decreased NSAID use } \\
\text { in PEMF group; no difference by } 24 \text { months }\end{array}$ & Hamstring & Attrition \\
\hline $\begin{array}{l}\text { Cincinnati knee score, functional } \\
\text { scale, range of motion, hop test }\end{array}$ & $\begin{array}{l}\text { No differences between groups } \\
\text { after } 6 \text { weeks }\end{array}$ & BTB & Selection \\
\hline Biodex stability system & Improved scores in balance group & Hamstring autograft & Treatment \\
\hline $\begin{array}{l}\text { Quadriceps strength, hop test, KOS-ADLS, } \\
\text { global rating scale, pass vs. fail return to sport }\end{array}$ & $\begin{array}{l}\text { No clinically significant differences } \\
\text { between groups at } 3,6 \text {, or } 12 \text { months }\end{array}$ & $\begin{array}{l}\text { Hamstring autograft } \\
\text { or allograft }\end{array}$ & \\
\hline
\end{tabular}

differences were significant, tunnel enlargement was not correlated with clinical outcomes in a previous study ${ }^{22}$.

Based on the findings presented in this section, immediate postoperative weight-bearing, range of knee motion from $0^{\circ}$ to $90^{\circ}$ of flexion, and strengthening with closed-chain exercises are likely safe. Starting eccentric quadriceps strengthening and isokinetic hamstring strengthening at week three after ACL surgery may improve or accelerate strength gains. Further investigation of accelerated, aggressive rehabilitation and its ability to shorten the return-to-sport time frame is warranted.

\section{Home-Based Rehabilitation}

Four studies included in the previous systematic reviews had evaluated home-based compared with outpatient physical therapy for rehabilitation after ACL reconstruction ${ }^{1,2}$. Despite flaws in reporting and study design that resulted in biases, the studies indicated that a motivated patient could obtain reasonable results with minimally supervised home-based rehabilitation. Two additional studies have subsequently evaluated home-based rehabilitation (Table IV).

Grant and Mohtadi provided longer-term data ${ }^{16}$ on a previously included trial comparing home-based rehabilitation that had minimal therapist involvement (four sessions) with physical therapist-guided rehabilitation (seventeen sessions) ${ }^{23}$. Eighty-eight $(68 \%)$ of the original 129 patients returned for follow-up between twenty-six and fifty-nine months (loss to follow-up, 32\%). A blinded examiner evaluated range of motion, laxity measured with the KT1000, isokinetic hamstring and quadriceps tests, and the ACL-QOL. No significant difference was noted in any parameter except the ACL-QOL (80.0 in the home therapy group compared with 69.9 in the physical therapist group, $\mathrm{p}=0.02$ ). One physical therapist treated all patients in the home therapy group, but each physical therapy group chose its own outside therapist, resulting in a performance bias. On the basis of these findings, home-based rehabilitation may be effective.

Revenas et al. compared randomized participation in a knee therapy class (twenty-four patients) with individual physical therapy appointments (twenty-seven patients) ${ }^{24}$ beginning six weeks after surgery. Both groups performed the same open and closed-kinetic-chain exercises with progressive increases in weight. The knee therapy class met twice weekly until six months postoperatively, and patients were included in the analysis if they attended $\geq 30 \%$ of the sessions (with $58 \%$ meeting this compliance standard and attending a median of fifteen sessions [range, thirteen to thirty-six]). The other group performed exercises on their own at least twice weekly and attended individual therapy sessions at the discretion of the therapist (median, three visits; range, two to twelve visits). Individuals in this group were included in the analysis if they attended at least one session between seven weeks and six months after surgery, and $89 \%$ met this compliance standard. An independent examiner evaluated IKDC, Lysholm, and Tegner scores; isometric strength; and the hop test at six and twelve months and found no significant differences. The two groups differed with regard to the preoperative Lysholm score and meniscal status. Because of performance bias (a wide range of compliance and a low threshold to be considered compliant) and attrition bias, it is difficult to draw any conclusions regarding this study.

\section{Neuromuscular Training}

Nine randomized trials evaluated neuromuscular training as part of rehabilitation after ACL reconstruction (Table V) ${ }^{17,25-32}$. 


\begin{abstract}
Study (Level of Evidence)
\end{abstract}
Barker et al. ${ }^{35}$ (II)

Huang et al. ${ }^{36}$ (II)

Dauty et al. ${ }^{37}$ (II)

Friemert et al. ${ }^{38}$ (II)

Maddison et al. ${ }^{39}$ (II)

Olivier et al. ${ }^{40}$ (II)
No. of Patients/Groups

$20 / 2$

$120 / 4$

$80 / 4$

$60 / 2$

$58 / 2$

$24 / 2$
Group Differences

Vitamin $\mathrm{E}$ and $\mathrm{C}$ supplement vs. placebo

Hyaluronic acid injection at 4 vs. 8 vs. 12 weeks vs. placebo

Two months of running retraining vs. control

CPM vs. CAM

Instructional video vs. control

One-leg cycling vs. control
Not stated

Not stated

Randomization

Not stated

Computer randomization

Not stated

Drawing lots

*BTB = bone-patellar tendon-bone, $\mathrm{CPM}=$ continuous passive motion, CAM = continuous active motion, IKDC = International Knee Documentation Committee, EDV = end-diastolic volume, and SV = stroke volume.

The training included proprioceptive and balance training, perturbation training, and vibratory stimulation.

Risberg et al. performed a randomized controlled trial involving seventy-four patients that compared six months of neuromuscular training with strengthening ${ }^{25}$. Patients were followed for two years ${ }^{17}$. A blinded assessor evaluated the Cincinnati knee score, VAS pain and function, Short Form-36 (SF-36), hop test, isokinetic strength, proprioception as indicated by the threshold for detection of passive motion, static and dynamic balance, and laxity measured with the KT1000. Four patients (5\%) were lost to follow-up at six months, nine (12\%) at one year, and fourteen (19\%) at two years. The neuromuscular training group had better Cincinnati knee scores at six months (80.5 compared with 73.4, p < $0.05)$ and VAS function at six months (72.4 compared with $59.3, \mathrm{p}<0.05)$ and one year $(81.8$ compared with $65.2, \mathrm{p}<$ $0.05)$. There was no difference in either parameter by two years $(\mathrm{p}<0.05)$, and the difference in the Cincinnati knee score was not clinically significant ${ }^{33}$. Knee flexion strength was higher in the strengthening group at one and two years. By two years, six patients required additional surgery, which consisted of one meniscectomy in each group, one revision for rerupture and one patellar tendon lengthening in the neuromuscular training group, and two arthroscopic surgical procedures for knee motion in an unstated group. No statistical analysis was performed to evaluate the difference in additional surgery between the groups.

Brunetti et al. performed a randomized, double-blind, placebo-controlled trial to evaluate whether vibratory stimulation could cause complex electrical and mechanical stimuli shown to improve proprioception ${ }^{30}$. Vibratory treatment con- sisted of mechanical vibration at a $100-\mathrm{Hz}$ frequency and $<20$ $\mu \mathrm{m}$ amplitude applied for thirty minutes on three consecutive days to the distal aspect of the quadriceps muscle of the operatively treated leg one month after surgery. Thirty patients were divided into two groups and evaluated at one, ten, ninety, and 270 days after treatment by single-leg balance and isokinetic quadriceps torque testing. Single-leg balance improved significantly in the vibration group $(\mathrm{p}<0.05)$ and was closer to the value in the uninjured limb than the value in the control group was. Peak extensor torque also improved significantly in the vibration group at ninety and 270 days. No clinically significant differences were noted in the IKDC or SF-36.

Moezy et al. compared four weeks of whole-body vibration training with strength training twelve weeks after ACL reconstruction $^{31}$. The twelve patients in the vibration training group performed barefoot static and dynamic squats and singleleg stance on a vibration platform whose frequency increased from 30 to $50 \mathrm{~Hz}$, amplitude increased from 2.5 to $5 \mathrm{~mm}$, and duration increased from four to sixteen minutes over twelve sessions. The eleven patients in the strength training group performed progressive strengthening exercises of major muscle groups. The patients were evaluated prior to and immediately following therapy, utilizing the Biodex stability system to measure postural stability and the knee repositioning test to measure proprioception. Patients in the vibration training group had greater improvements in all stability indices $(\mathrm{p}<0.05)$ and proprioception $(p<0.05)$. Without long-term data, it is not known whether these effects were lasting.

Benazzo et al. evaluated sixty-nine patients who received either a pulsed electromagnetic field (a magnetic field strength of $1.5 \mathrm{mT}$ at $75 \mathrm{~Hz})$ for two hours daily for two months $(\mathrm{n}=31)$ or 
TABLE VI (continued)

\begin{tabular}{|c|c|c|c|}
\hline Parameters Assessed & Significant Findings & ACL Method & Bias \\
\hline $\begin{array}{l}\text { Lysholm, peak torque, range } \\
\text { of motion, ambulation speed }\end{array}$ & $\begin{array}{l}\text { Hyaluronic acid injection at } \\
8 \text { weeks gave largest improvement } \\
\text { in ambulation speed and peak } \\
\text { torque }\end{array}$ & Not stated & \\
\hline $\begin{array}{l}\text { Laxity with KT1000, } \\
\text { Lysholm, Tegner, isokinetic } \\
\text { strength }\end{array}$ & $\begin{array}{l}\text { Strength differences depending on } \\
\text { ACL reconstruction method; no } \\
\text { return-to-sport data }\end{array}$ & BTB, hamstring & Performance, selection \\
\hline Joint position sense & CAM improved $2.2^{\circ}$ more & BTB, hamstring & Selection, attrition \\
\hline $\begin{array}{l}\text { Anxiety, pain, functional outcomes, } \\
\text { IKDC }\end{array}$ & $\begin{array}{l}\text { Video decreased pain, } \\
\text { increased self-efficacy }\end{array}$ & Not stated & Underpowered \\
\hline
\end{tabular}

a placebo treatment $(n=29)$ starting within seven days after ACL reconstruction $^{32}$. Nine patients did not complete the treatment and were not included in the analysis. Assessment included IKDC, SF-36, and VAS pain and function scores as well as utilization of nonsteroidal anti-inflammatory drugs (NSAIDs) at one, two, six, and twenty-four months after surgery. Patients in the treatment group had significantly faster recovery as measured by the SF-36 score and decreased NSAID use $(\mathrm{p}<0.05)$. However, no differences persisted at twenty-four months.

Cooper et al. compared six weeks of strength training with proprioceptive and balance training in twenty-nine randomized patients ${ }^{26}$. Patients were evaluated on the basis of the Cincinnati knee score, patient-specific functional scale, knee motion, and hop test after completion of the six weeks of treatment. No difference between the groups was noted.

Vathrakokilis et al. performed a randomized controlled trial comparing eight weeks of balance training with a standard rehabilitation protocol of strengthening and range-of-motion exercises $^{27}$. Twenty-four patients were evaluated with the Biodex stability system and two different kinds of balance boards before and after the intervention. (The balance board model was changed during the study period.) Outcomes included overall knee stability, anterior-posterior stability, and mediallateral stability in addition to the measured stability time for both the operatively treated and the uninjured leg. The score in the balance-training group improved after the intervention. No significance values were given, and the randomization method was not described.

Hartigan et al. compared ten sessions of perturbation training and quadriceps strengthening $(n=9)$ with quadriceps strengthening alone $(n=10)$ for three weeks prior to ACL reconstruction in nineteen patients ${ }^{28}$. The perturbation train- ing involved balancing on a surface that was moved or perturbed by the therapist. Maximum volitional quadriceps isometric contraction and knee excursion during midstance of gait were evaluated preoperatively and at six months postoperatively. Prior to the intervention, the quadriceps strength index in the nine patients in the perturbation group $(87.2 \%)$ differed from that in the ten patients in the strengthening group $(75.8 \%)$, but this was not discussed in the article. Both groups had improvement in strength at the final evaluation (to $97.1 \%$ in the perturbation group and $94.4 \%$ in the strengthening group); the larger improvement demonstrated in the strengthening group was not addressed in the article. Prior to intervention, midstance knee excursion was decreased compared with that in the uninjured limb in both groups but was similar between groups $\left(5.9^{\circ}\right.$ in the perturbation group, $\mathrm{p}=0.026 ; 5.6^{\circ}$ in the strengthening group, $\mathrm{p}=0.031)$. Six months postoperatively, the perturbation group demonstrated no difference between the operatively treated and the uninjured $\operatorname{limb}\left(3.5^{\circ}, \mathrm{p}=0.14\right)$, whereas the strengthening group continued to have decreased knee excursion $\left(7.0^{\circ}, \mathrm{p}=0.007\right)$.

In a second study, Hartigan et al. evaluated the same nineteen patients plus an additional twenty-one patients with use of the quadriceps strength index, hop test, KOS-ADLS score, global rating scale, and attainment of return-to-sports criteria at three, six, and twelve months postoperatively ${ }^{29}$. Nine patients $(23 \%)$ were lost to follow-up at three months, ten $(25 \%)$ at six months, and twelve $(30 \%)$ at twelve months. The groups were similar prior to the intervention and had similar quadriceps strength gains. At three months, there were no differences between the groups. At six months, the perturbation group had a significantly greater KOS-ADLS score (97.9 compared with 95.9, $\mathrm{p}=0.029)$ and global rating scale score (94.3 compared with 90.0, $\mathrm{p}=0.047$ ), although neither difference was clinically significant ${ }^{34}$. The percentage of patients 
The Journal of Bone \& Joint Surgery · Jbjs.org Volume 94-A • Number 19. OCtober 3, 2012
Rehabilitation After Anterior Cruciate

LigAMENT RECONSTRUCTION meeting return-to-sport criteria (values of $\geq 90 \%$ for the quadriceps strength index, hop index, KOS-ADLS, and global rating of knee function) did not differ between the groups.

On the basis of the studies presented above, we conclude that neuromuscular interventions are unlikely to be harmful. Additionally, they are unlikely to make large improvements in outcomes or to help patients return to sports faster. Neuromuscular training may provide small benefits but should not be performed to the exclusion of strengthening and knee rangeof-motion exercises. Vibration training may lead to faster and more complete proprioceptive recovery, but further evidence is needed.

\section{Miscellaneous}

Six studies addressed a variety of other issues in rehabilitation after ACL reconstruction (Table VI) ${ }^{35-40}$.

Barker et al. evaluated vitamin-E and vitamin-C supplementation compared with a placebo in a randomized trial of twenty subjects who had undergone ACL reconstruction ${ }^{35}$. Patients received either placebo or vitamin supplementation twice a day. No difference between the groups was demonstrated in single-leg isometric strength preoperatively or at three months postoperatively or in thigh circumference preoperatively or at five days postoperatively. Muscle biopsy specimens taken prior to surgery and on postoperative day five were evaluated for cross-sectional area, composition, and markers of inflammatory cell infiltration (myeloperoxidase, inducible nitric oxide synthase [iNOS], and calpains). Muscle fiber area and composition did not differ between the groups, but markers of inflammatory cell infiltration were significantly greater in the treatment group $(\mathrm{p}<0.05)$. Increased baseline vitamin- $\mathrm{C}$ status correlated with improved isometric muscle strength recovery at three months. There was no discussion of randomization, use of an independent examiner, attrition, or power analysis. The sample size of twenty subjects may have been underpowered to detect a difference. Thus, further studies are needed before we can recommend for or against such vitamin supplementation following ACL reconstruction.

Huang et al. tested intra-articular hyaluronic acid injections during recovery from ACL reconstruction in 120 patients without meniscal or chondral injuries who were randomized to four groups ${ }^{36}$. The three treatment groups received three weekly hyaluronic acid injections starting at postoperative week four, eight, or twelve. The placebo group received three weekly placebo injections. The Lysholm score, peak muscle torque, knee motion, and ambulation speed were measured at four, eight, twelve, and sixteen weeks and one year postoperatively. Patients who received injections starting at eight weeks had higher Lysholm scores (mean, $86 \pm 15$ compared with $65 \pm 14$ in the controls; $\mathrm{p}<0.05)$ and greater knee motion at one year (mean, $136^{\circ} \pm 22^{\circ}$ compared with $105^{\circ} \pm 28^{\circ}$ in the controls; $\left.\mathrm{p}<0.05\right)$ than the other groups. All groups improved in ambulation speed (as measured by the $50-\mathrm{m}$ walk time) and peak muscle torque, but greater improvements occurred in the groups treated with hyaluronic acid, with the group treated at eight weeks having the largest improvement. On the basis of these findings, postoperative hyaluronic acid injections, especially at eight weeks, may improve outcomes following reconstruction. However, cost and insurance approval issues may make this impractical for the patient undergoing routine ACL reconstruction.

Dauty et al. compared patients in a two-month runningretraining program with controls after ACL reconstruction. The study included eighty male patients (twenty-one retrained and twenty controls after use of patellar tendon autograft, and nineteen retrained and twenty controls after use of hamstring autograft $)^{37}$. Running retraining occurred between the fourth and sixth weeks after surgery and involved interval training of progressively increasing duration and intensity. There were no differences in KT1000, Lysholm, and Tegner scores between the groups after two months of training. The patellar tendon group had weaker isokinetic strength in extension, and the hamstring group had weaker isokinetic strength in flexion. This study had potential performance and selection biases. It is unclear whether running was permitted or prohibited in the control group, and compliance data were not presented.

Friemert et al. randomized sixty patients during the first week after ACL reconstruction to use of either a continuous passive motion machine or a continuous active motion machine. All patients underwent three one-hour sessions per day during the first week after surgery, and the impact on recovery of joint position sense was evaluated ${ }^{38}$. The range-of-motion settings in this study were not stated. An electrogoniometer measured joint position sense preoperatively and at seven days postoperatively, with the uninjured knee used as a control. The two groups were similar preoperatively, but after treatment the continuous active motion group had $2.2^{\circ}$ greater improvement in joint position sense compared with the continuous passive motion group $(\mathrm{p}=$ $0.0001)$. The authors concluded that the $2.2^{\circ}$ represented a clinically significant difference on the basis of previous work correlating improved proprioception and patient satisfaction ${ }^{41,42}$. Several issues in this study led to potential biases; $>90 \%$ of patients were male, attrition was not mentioned, and there was no discussion of randomization or use of an independent examiner. In the absence of long-term follow-up, it is unknown whether these findings would persist and whether they resulted in a clinically significant difference in return to sports. Because of the questions surrounding this study, we do not recommend use of continuous active motion on a routine basis.

Maddison et al. examined the effects of an instructional video on anxiety, pain, and functional outcomes in fifty-eight randomized patients, thirty who received the intervention and twenty-eight controls who did not ${ }^{39}$. Subjects in the intervention group watched two videos describing treatment preoperatively and at six weeks postoperatively. All patients were asked to rate anxiety, expected pain, and expected self-efficacy (confidence in performing the rehabilitation exercises), and an IKDC score was obtained. Participants who watched the videos demonstrated less expected pain $(p<0.05)$ and greater expected self-efficacy in the domains of crutch use $(\mathrm{p}<0.01)$ and ability to perform exercises $(p<0.05)$ at the time of hospital discharge. There was 
The Journal of Bone \& Joint Surgery · Jbjs.org Volume 94-A - Number $19 \cdot$ OCtober 3, 2012
Rehabilitation After Anterior Cruciate

LIGAMENT RECONSTRUCTION no difference in the domain of walking confidence at that time or in any domain at the time of final follow-up. Additionally, the IKDC objective scores was significantly higher in the intervention group ( $\mathrm{p}=0.01)$, but the difference of $<1$ point was not clinically significant ${ }^{20}$. Video teaching may be helpful in decreasing early expectations of pain and increasing early expectations of selfefficacy after ACL reconstruction.

Olivier et al. randomized twenty-four regional-level soccer players to either a one-leg cycling group or a control group to evaluate the effects on cardiorespiratory fitness ${ }^{40}$. Both groups received rehabilitation; training in the treatment group included one-leg cycling utilizing the untreated leg, whereas the control group did not undergo aerobic training. Patients had therapy three times per week for six weeks after surgery (which was performed approximately two months after injury), and evaluations were performed at baseline and at six weeks by a blinded examiner. Echocardiography at rest was used to evaluate end-diastolic volume and stroke volume, and maximal graded tests using a standard bicycle ergometer were used to evaluate peak work rate, oxygen uptake, ventilation per minute, leg muscle oxygenation, and leg muscle blood volume. The two groups had no differences at baseline. The treatment group had increases in ventilation per minute and peak work rate at six weeks, whereas the control group had decreases $(\mathrm{p}<0.05)$. Additionally, stroke volume and enddiastolic volume were unchanged in the treatment group but decreased significantly $(\mathrm{p}<0.05)$ by $21 \%$ and $16 \%$, respectively, in the control group. After six weeks, the control group had decreased aerobic fitness $(\mathrm{p}<0.05)$, but the treatment group maintained their baseline aerobic fitness. Measurement bias may be present since the initial measurements were made two months after injury, and selection bias may be present since all patients were male soccer players. Single-leg cycling may be a beneficial option to maintain cardiovascular fitness during rehabilitation after ACL reconstruction.

\section{Source of Funding}

No outside funding was utilized in this study.

\section{$\mathrm{N}^{2}$}

Discussion umerous aspects of rehabilitation following ACL reconstruction have been investigated with Level-I and II clinical trials. As with most systematic reviews, inclusion of published studies often involves a publication bias in favor of positive findings. This is less relevant when studying rehabilitation, as both positive and negative findings are deemed important.

Although many of the included studies have a selection bias, it is still possible to draw some valuable conclusions.
Multiple types of bracing were evaluated, including knee immobilization, rehabilitation bracing, and functional bracing. Overall, no brace or length of brace wear demonstrated an advantage over another type of brace, another duration of bracing, or no bracing at all. Bracing does not provide any benefit and is not necessary. Accelerated rehabilitation has shown no deleterious effects, and it is likely safe for patients to begin immediate postoperative weight-bearing, move the knee from $0^{\circ}$ to $90^{\circ}$ of flexion, and perform closed-chain strengthening exercises. Eccentric quadriceps muscle strengthening and isokinetic hamstring muscle strengthening were safely incorporated three weeks after surgery; they may be safe sooner, but further research is needed. Home-based rehabilitation can be effective.

Neuromuscular exercises are not likely to be harmful to patients; however, their impact was small, making them unlikely to yield large improvements in outcomes or help patients return to sports faster. Neuromuscular exercises should not be performed to the exclusion of strengthening and range-ofmotion exercises. Neither supplemental vitamin $\mathrm{C}$ nor vitamin $\mathrm{E}$ appears to be beneficial. Postoperative hyaluronic acid injections may improve some measurable parameters, but their cost must be kept in mind. Single-leg cycling to maintain cardiac fitness may be beneficial. Continuous passive motion is still not recommended.

The studies presented in this paper focused on improving rehabilitation following ACL reconstruction, with a goal of safely allowing expeditious return of mobility, strength, and ultimately sport participation. However, few studies actually measured the ability to return to sports and its timing following the interventions. The availability of such data could strengthen the conclusions of studies and should be considered in future research. Despite the large number of randomized trials, further investigations of the timing of rehabilitation and supplemental rehabilitation exercises are needed to continue to improve the care and function of patients following ACL reconstruction.

L.M. Kruse, MD

B. Gray, MD

R.W. Wright, MD

Department of Orthopedic Surgery,

Washington University School of Medicine,

660 South Euclid Avenue, Campus Box 8233,

St. Louis, MO 63110.

E-mail address for R.W. Wright: wright@wudosis.wustl.edu

\section{References}

1. Wright RW, Preston E, Fleming BC, Amendola A, Andrish JT, Bergfeld JA, Dunn WR, Kaeding C, Kuhn JE, Marx RG, McCarty EC, Parker RC, Spindler KP, Wolcott M, Wolf BR, Williams GN. A systematic review of anterior cruciate ligament reconstruction rehabilitation: part II: open versus closed kinetic chain exercises, neuromuscular electrical stimulation, accelerated rehabilitation, and miscellaneous topics. J Knee Surg. 2008 Jul;21(3):225-34 2. Wright RW, Preston E, Fleming BC, Amendola A, Andrish JT, Bergfeld JA, Dunn WR, Kaeding C, Kuhn JE, Marx RG, McCarty EC, Parker RC, Spindler KP, Wolcott M,
Wolf BR, Williams GN. A systematic review of anterior cruciate ligament reconstruction rehabilitation: part I: continuous passive motion, early weight bearing, postoperative bracing, and home-based rehabilitation. J Knee Surg. 2008 Jul;21(3):217-24.

3. Isberg J, Faxén E, Brandsson S, Eriksson BI, Kärrholm J, Karlsson J. Early active extension after anterior cruciate ligament reconstruction does not result in increased 
The Journal of Bone \& Joint Surgery - jbjs.org Volume 94-A - Number $19 \cdot$ OCtober 3, 2012
Rehabilitation After Anterior Cruciate

LIGAMENT RECONSTRUCTION laxity of the knee. Knee Surg Sports Traumatol Arthrosc. 2006 Nov;14(11):1108-15. Epub 2006 Sep 6.

4. Ito Y, Deie M, Adachi N, Kobayashi K, Kanaya A, Miyamoto A, Nakasa T, Ochi M. A prospective study of 3-day versus 2-week immobilization period after anterior cruciate ligament reconstruction. Knee. 2007 Jan;14(1):34-8. Epub 2006 Nov 28.

5. Beynnon BD, Un BS, Johnson RJ, Abate JA, Nichols CE, Fleming BC, Poole AR, Roos $\mathrm{H}$. Rehabilitation after anterior cruciate ligament reconstruction: a prospective, randomized, double-blind comparison of programs administered over 2 different time intervals. Am J Sports Med. 2005 Mar;33(3):347-59.

6. Shaw T, Williams MT, Chipchase LS. Do early quadriceps exercises affect the outcome of ACL reconstruction? A randomised controlled trial. Aust J Physiother. 2005;51(1):9-17.

7. Sekir U, Gur H, Akova B. Early versus late start of isokinetic hamstringstrengthening exercise after anterior cruciate ligament reconstruction with patellar tendon graft. Am J Sports Med. 2010 Mar;38(3):492-500.

8. Gerber JP, Marcus RL, Dibble LE, Greis PE, Burks RT, LaStayo PC. Effects of early progressive eccentric exercise on muscle structure after anterior cruciate ligament reconstruction. J Bone Joint Surg Am. 2007 Mar;89(3):559-70.

9. Gerber JP, Marcus RL, Dibble LE, Greis PE, Burks RT, LaStayo PC. Effects of early progressive eccentric exercise on muscle size and function after anterior cruciate ligament reconstruction: a 1-year follow-up study of a randomized clinical trial. Phys Ther. 2009 Jan;89(1):51-9. Epub 2008 Nov 6.

10. Gerber JP, Marcus RL, Dibble LE, Greis PE, Burks RT, Lastayo PC. Safety, feasibility, and efficacy of negative work exercise via eccentric muscle activity following anterior cruciate ligament reconstruction. J Orthop Sports Phys Ther. 2007 Jan;37(1):10-8.

11. Vadalà A, lorio R, De Carli A, Argento G, Di Sanzo V, Conteduca F, Ferretti A. The effect of accelerated, brace free, rehabilitation on bone tunnel enlargement after ACL reconstruction using hamstring tendons: a CT study. Knee Surg Sports Traumatol Arthrosc. 2007 Apr;15(4):365-71. Epub 2006 Dec 6.

12. Hiemstra LA, Heard SM, Sasyniuk TM, Buchko GL, Reed JG, Monteleone BJ. Knee immobilization for pain control after a hamstring tendon anterior cruciate ligament reconstruction: a randomized clinical trial. Am J Sports Med. 2009 Jan;37(1):56-64. Epub 2008 Sep 18.

13. Birmingham TB, Bryant DM, Giffin JR, Litchfield RB, Kramer JF, Donner A, Fowler PJ. A randomized controlled trial comparing the effectiveness of functional knee brace and neoprene sleeve use after anterior cruciate ligament reconstruction. Am J Sports Med. 2008 Apr;36(4):648-55. Epub 2008 Jan 11.

14. Mayr HO, Hochrein A, Hein W, Hube R, Bernstein A. Rehabilitation results following anterior cruciate ligament reconstruction using a hard brace compared to a fluid-filled soft brace. Knee. 2010 Mar;17(2):119-26. Epub 2009 Aug 13.

15. Harilainen A, Sandelin J. Post-operative use of knee brace in bone-tendon-bone patellar tendon anterior cruciate ligament reconstruction: 5-year follow-up results of a randomized prospective study. Scand J Med Sci Sports. 2006 Feb;16(1):14-8.

16. Grant JA, Mohtadi NG. Two- to 4-year follow-up to a comparison of home versus physical therapy-supervised rehabilitation programs after anterior cruciate ligament reconstruction. Am J Sports Med. 2010 Jul;38(7):1389-94. Epub 2010 Apr 1. 17. Risberg MA, Holm I. The long-term effect of 2 postoperative rehabilitation programs after anterior cruciate ligament reconstruction: a randomized controlled clinical trial with 2 years of follow-up. Am J Sports Med. 2009 Oct;37(10):1958-66. Epub 2009 Jun 25.

18. Phillips B, Ball C, Sackett D, Badenoch D, Straus S, Haynes B, Dawes M. Levels of evidence. 2009. http://www.cebm.net/index.aspx?o=1025. Accessed 26 Nov 2011. 19. Schulz KF, Altman DG, Moher D; CONSORT Group. CONSORT 2010 Statement: updated guidelines for reporting parallel group randomised trials. J Clin Epidemiol. 2010 Aug;63(8):834-40. Epub 2010 Mar 25.

20. Irrgang JJ, Anderson AF, Boland AL, Harner CD, Neyret P, Richmond JC, Shelbourne KD; International Knee Documentation Committee. Responsiveness of the International Knee Documentation Committee Subjective Knee Form. Am J Sports Med. 2006 Oct;34(10):1567-73. Epub 2006 Jul 26.

21. Briggs KK, Steadman JR, Hay CJ, Hines SL. Lysholm score and Tegner activity level in individuals with normal knees. Am J Sports Med. 2009 May;37(5):898-901. Epub 2009 Mar 23.

22. Clatworthy MG, Annear P, Bulow JU, Bartlett RJ. Tunnel widening in anterior cruciate ligament reconstruction: a prospective evaluation of hamstring and patella tendon grafts. Knee Surg Sports Traumatol Arthrosc. 1999;7(3):138-45.

23. Grant JA, Mohtadi NG, Maitland ME, Zernicke RF. Comparison of home versus physical therapy-supervised rehabilitation programs after anterior cruciate ligament reconstruction: a randomized clinical trial. Am J Sports Med. 2005 Sep;33(9): 1288-97. Epub 2005 Jul 7.
24. Revenas A, Johansson A, Leppert J. A randomized study of two physiotherapeutic approaches after knee ligament reconstruction. Adv Physiother. 2009;11: 30-41.

25. Risberg MA, Holm I, Myklebust G, Engebretsen L. Neuromuscular training versus strength training during first 6 months after anterior cruciate ligament reconstruction: a randomized clinical trial. Phys Ther. 2007 Jun;87(6):737-50. Epub 2007 Apr 18.

26. Cooper RL, Taylor NF, Feller JA. A randomised controlled trial of proprioceptive and balance training after surgical reconstruction of the anterior cruciate ligament. Res Sports Med. 2005 Jul-Sep;13(3):217-30.

27. Vathrakokilis K, Malliou P, Gioftsidou A, Beneka A, Godolias G. Effects of a balance training protocol on knee joint proprioception after anterior cruciate ligament reconstruction. J Back Musculoskeletal Rehabil. 2008;21(4):233-7.

28. Hartigan E, Axe MJ, Snyder-Mackler L. Perturbation training prior to $A C L$ reconstruction improves gait asymmetries in non-copers. J Orthop Res. 2009 Jun;27(6): 724-9.

29. Hartigan EH, Axe MJ, Snyder-Mackler L. Time line for noncopers to pass returnto-sports criteria after anterior cruciate ligament reconstruction. J Orthop Sports Phys Ther. 2010 Mar;40(3):141-54.

30. Brunetti O, Filippi GM, Lorenzini M, Liti A, Panichi R, Roscini M, Pettorossi VE, Cerulli G. Improvement of posture stability by vibratory stimulation following anterior cruciate ligament reconstruction. Knee Surg Sports Traumatol Arthrosc. 2006 Nov;14(11):1180-7. Epub 2006 Jun 9.

31. Moezy A, Olyaei G, Hadian M, Razi M, Faghihzadeh S. A comparative study of whole body vibration training and conventional training on knee proprioception and postural stability after anterior cruciate ligament reconstruction. $\mathrm{Br} J$ Sports Med. 2008 May;42(5):373-8. Epub 2008 Jan 8.

32. Benazzo F, Zanon G, Pederzini L, Modonesi F, Cardile C, Falez F, Ciolli L, La Cava F, Giannini S, Buda R, Setti S, Caruso G, Massari L. Effects of biophysical stimulation in patients undergoing arthroscopic reconstruction of anterior cruciate ligament: prospective, randomized and double blind study. Knee Surg Sports Traumatol Arthrosc. 2008 Jun;16(6):595-601. Epub 2008 Apr 2.

33. Greco NJ, Anderson AF, Mann BJ, Cole BJ, Farr J, Nissen CW, Irrgang JJ. Responsiveness of the International Knee Documentation Committee Subjective Knee Form in comparison to the Western Ontario and McMaster Universities Osteoarthritis Index, modified Cincinnati Knee Rating System, and Short Form 36 in patients with focal articular cartilage defects. Am J Sports Med. 2010 May;38(5):891-902. Epub 2009 Dec 31.

34. Marx RG, Jones EC, Allen AA, Altchek DW, O'Brien SJ, Rodeo SA, Williams RJ, Warren RF, Wickiewicz TL. Reliability, validity, and responsiveness of four knee outcome scales for athletic patients. J Bone Joint Surg Am. 2001 Oct;83-A(10): 1459-69.

35. Barker T, Leonard SW, Hansen J, Trawick RH, Ingram R, Burdett G, Lebold KM, Walker JA, Traber MG. Vitamin E and C supplementation does not ameliorate muscle dysfunction after anterior cruciate ligament surgery. Free Radic Biol Med. 2009 Dec 1:47(11):1611-8. Epub 2009 Sep 12.

36. Huang MH, Yang RC, Chou PH. Preliminary effects of hyaluronic acid on early rehabilitation of patients with isolated anterior cruciate ligament reconstruction. Clin J Sport Med. 2007 Jul;17(4):242-50.

37. Dauty M, Menu P, Dubois $\mathrm{C}$. Effects of running retraining after knee anterior cruciate ligament reconstruction. Ann Phys Rehabil Med. 2010 Apr;53(3):150-61. Epub 2010 Jan 16.

38. Friemert B, Bach C, Schwarz W, Gerngross H, Schmidt R. Benefits of active motion for joint position sense. Knee Surg Sports Traumatol Arthrosc. 2006 Jun;14(6):564-70. Epub 2005 Nov 23.

39. Maddison R, Prapavessis H, Clatworthy M. Modeling and rehabilitation following anterior cruciate ligament reconstruction. Ann Behav Med. 2006 Feb;31(1):89-98.

40. Olivier N, Weissland T, Legrand R, Berthoin S, Rogez J, Thevenon A, Prieur F. The effect of a one-leg cycling aerobic training program during the rehabilitation period in soccer players with anterior cruciate ligament reconstruction. Clin J Sport Med. 2010 Jan;20(1):28-33.

41. Katayama M, Higuchi $H$, Kimura $M$, Kobayashi A, Hatayama K, Terauchi $M$, Takagishi K. Proprioception and performance after anterior cruciate ligament rupture. Int Orthop. 2004 Oct;28(5):278-81. Epub 2004 Aug 26.

42. Fremerey RW, Lobenhoffer P, Born I, Tscherne H, Bosch U. [Can knee joint proprioception by reconstruction of the anterior cruciate ligament be restored? A prospective longitudinal study]. Unfallchirurg. 1998 Sep;101(9):697-703. German. 